\title{
CARGEL Bioscaffold improves cartilage repair tissue after bone marrow stimulation in a minipig model
}

\author{
K. Hede ${ }^{1 *}$ (D, B. B. Christensen ${ }^{1}$, M. L. Olesen', J. S. Thomsen², C. B. Foldager ${ }^{1}$ and M. C. Lind ${ }^{1,3}$
}

\begin{abstract}
Purpose: To gain knowledge of the repair tissue in critically sized cartilage defects using bone marrow stimulation combined with CARGEL Bioscaffold (CB) compared with bone marrow stimulation (BMS) alone in a validated animal model.

Methods: Six adult Göttingen minipigs received two chondral defects in each knee. The knees were randomized to either BMS combined with CB or BMS alone. The animals were euthanized after 6 months. Follow-up consisted of histomorphometry, immunohistochemistry, semiquantitative scoring of the repair tissue (ICRS II), and $\mu \mathrm{CT}$ of the trabecular bone beneath the defect.

Results: There was significantly more fibrocartilage ( $80 \%$ vs $64 \%, p=0.04)$ and a trend towards less fibrous tissue $(15 \%$ vs $30 \%, p=0.05)$ in the defects treated with CB. Hyaline cartilage was only seen in one defect treated with CB and none treated with BMS alone.

For histological semiquantitative score (ICRS II), defects treated with CB scored lower on subchondral bone (69 vs. $44, p=0.04)$. No significant differences were seen on the other parameters of the ICRS II. Immunohistochemistry revealed a trend towards more positive staining for collagen type II in the CB group $(p=0.08)$. $\mu C T$ demonstrated thicker trabeculae $(p=0.029)$ and a higher bone material density $(p=0.028)$ in defects treated with CB.

Conclusion: Treatment of cartilage injuries with CARGEL Bioscaffold seems to lead to an improved repair tissue and a more pronounced subchondral bone response compared with bone marrow stimulation alone. However, the CARGEL Bioscaffold treatment did not lead to formation of hyaline cartilage.
\end{abstract}

Keywords: Articular cartilage, Cartilage repair, Knee, Bone marrow stimulation, Microfracture, Drilling, Minipig

\section{Introduction}

Cartilage lesions are common and do not heal spontaneously due to the avascular and aneural nature of the tissue. Cartilage lesions can lead to pain and early osteoarthritis [1]. Bone marrow stimulation techniques (BMS) such as microfracture (Mfx) is the preferred treatment option for small, symptomatic cartilage lesions in the knee [2]. The rationale behind BMS is to allow bone marrow mesenchymal stem cells to migrate to the

\footnotetext{
* Correspondence: kch@clin.au.dk

${ }^{1}$ Orthopedic Research Laboratory, Aarhus University Hospital, Palle Juul-Jensens Boulevard 99, Section J, Level 1, 8200 Aarhus N, Denmark Full list of author information is available at the end of the article
}

lesion and to induce and facilitate a repair response. This treatment is surgically time-efficient, inexpensive, and have good short-term outcome. The repair response, however, consists primarily of fibrocartilage and fibrous tissue, which does not possess the same biomechanical properties as hyaline cartilage and is therefore more susceptible to wear causing deterioration of the early results [3]. While BMS can be a good treatment option for very small lesions augmentation is needed for larger lesions. The most common strategy for augmentation of BMS is to combine the procedure with cell-free scaffolds that may facilitate cartilage repair biomechanically and biologically. Numerous products have been introduced to

\section{Springer Open}

() The Author(s). 2020 Open Access This article is licensed under a Creative Commons Attribution 4.0 International License, which permits use, sharing, adaptation, distribution and reproduction in any medium or format, as long as you give appropriate credit to the original author(s) and the source, provide a link to the Creative Commons licence, and indicate if changes were made. The images or other third party material in this article are included in the article's Creative Commons licence, unless indicated otherwise in a credit line to the material. If material is not included in the article's Creative Commons licence and your intended use is not permitted by statutory regulation or exceeds the permitted use, you will need to obtain permission directly from the copyright holder. To view a copy of this licence, visit http://creativecommons.org/licenses/by/4.0/. 
the market, but early literature on their use is of limited quality [4].

Cartilage repair by $\mathrm{Mfx}$ is initiated by bone marrow-derived cells found in the blood clot, which fills the defect following penetration of the subchondral bone. Differences in blot clot stability may explain differences in repair tissue outcomes. CARGEL Bioscaffold (CB) (formerly BST CarGel; Smith \& Nephew) is a chitosan-based biomaterial used as an adjuvant to bone marrow stimulation. It has mostly been used with a mini-arthrotomy, but it has also been proposed for arthroscopic techniques [5]. The purpose of the chitosan scaffold is stabilization of the bone marrow clot in the cartilage lesion after bone marrow stimulation to allow formation of improved repair tissue [6-8]. CB combined with Mfx has proven safe and has shown superior repair tissue quantity and quality compared to Mfx after 5 years [9-11]. CB has also been used for cartilage lesions in the hip where it has also shown safety of use and superior patient outcomes compared with Mfx alone [12]. Furthermore, use of $\mathrm{CB}$ has been suggested to be a cost-saving alternative to Mfx due to greater improvements in the induction of cartilage repair tissue with hyaline characteristics [13]. However, clinical studies are limited in characterizing the biological and morphological characteristics of the repair tissue, which is one of the main predictors of long-term outcome. Animal studies of $\mathrm{CB}$ have mainly been conducted in smaller animal models where there is a tendency to spontaneous healing of cartilage defects $[7,8,14-17]$.

The aim of this study was to investigate and compare the morphological and histological effects of a combination of BMS and CB with BMS alone in chondral defects in the knees of Göttingen minipigs. The hypothesis was that treatment with $\mathrm{CB}$ would improve repair tissue quality compared with BMS.

\section{Materials and methods \\ Experimental design}

Six skeletally mature male Göttingen minipigs (weighing $38.4 \mathrm{~kg}$, range $36.4-43.6 \mathrm{~kg}$; aged 19.4 months, range 18.9-21.1 months) were included in the study. Two cylindrical chondral defects were created in the trochlea of each knee with a diameter of $6 \mathrm{~mm}$, which has been shown to be a critical size defect in Göttingen Minipigs [18]: One defect in the medial trochlear facet and one defect in the lateral trochlear facet. The defects of each knee were randomized to treatment with either marrow stimulation or marrow stimulation in combination with CB (Smith \& Nephew, Hørsholm, DK). The animals were euthanized after 6 months. Follow-up consisted of $\mu \mathrm{CT}$, histomorphometry, semiquantitative scoring of histology (International Cartilage Repair Society [ICRS II]), and immunohistochemistry.

The study was conducted according to the Danish Law on Animal Experimentation and approved by the Danish Ministry of Justice Ethical Committee (J.nr. 2017-150201-01343).

\section{Surgery}

The Göttingen mini-pig animal model has previously been described in detail [19-21]. Animals were premedicated with Zoletil Mix $1 \mathrm{~mL} / 10 \mathrm{~kg}$ (tiletamin $2.5 \mathrm{mg} / \mathrm{mL}$, zolazepam $2.5 \mathrm{mg} / \mathrm{mL}$, torbugesic $0.5 \mathrm{mg} / \mathrm{mL}$, ketaminol $2.5 \mathrm{mg} / \mathrm{mL}$, and rompun $2.5 \mathrm{mg} / \mathrm{mL}$; Virbac, DK). General anesthesia and local analgesia were achieved with Etomidate (Hypnomidate, $0.25 \mathrm{~mL} / \mathrm{kg}$; Janssen Pharmaceuticals), sevoflurane (3\%; AbbVie), fentanyl $(0.175 \mathrm{~mL} /$ $\mathrm{kg} / \mathrm{h}$, Hameln Pharmaceuticals), and Lidocaine (Xylocaine $10 \mathrm{~mL}, 20 \mathrm{mg} / \mathrm{mL}$; Astra Zeneca). Preoperative prophylactic antibiotics were used (penicillin procaine, $0.03 \mathrm{~mL} / \mathrm{kg}$; Ceva Sante Animale, France).

Access to the knee joint was gained through the patellar ligament. The trochlea was exposed, and two chondral defects with a diameter of $6 \mathrm{~mm}$ were created using a skin biopsy punch and a curette. One defect was made in the distal, medial trochlea, while the other was made in the lateral trochlea, 0.5 to $1 \mathrm{~cm}$ proximal to the first defect. This was done in all knees, and both defects in each knee were treated with the same method. The defects were thoroughly debrided by use of a curette, and the calcified cartilage layer was carefully removed in order not to damage the subchondral bone.

In the BMS group, four holes (depth $5 \mathrm{~mm}$, diameter $1 \mathrm{~mm}$ ) were drilled into the subchondral bone, and bleeding from the bone marrow was observed. In the group with marrow stimulation combined with $\mathrm{CB}$, bone marrow stimulation was performed as described above. The defect was then dried using a small swab (Fig. 1a). Meanwhile, the $\mathrm{CB}$ was prepared according to manufacturer's instructions with $4.5 \mathrm{~mL}$ of autologous venous blood, drawn from the ear vein. The leg was positioned to ensure a horizontal position of the defect. The $\mathrm{CB}$ was then injected, and the defect filled entirely with care taken not to overfill the defect $($ Fig. $1 b+C)$. The clot was

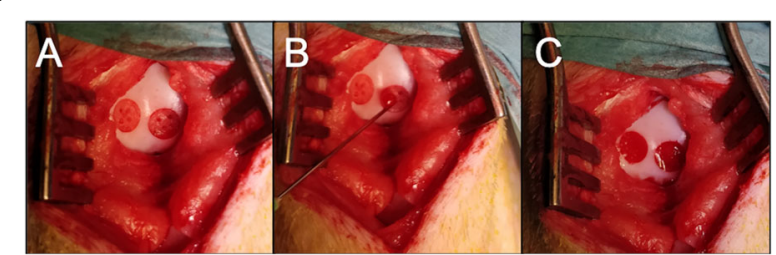

Fig. 1 a shows the defects after debridement, drilling and drying. $\mathbf{b}$ shows application of the CARGEL. $\mathbf{c}$ is immediately after the application 
allowed $15 \mathrm{~min}$ to stabilize and the knee was put through 40 full range of motion movements followed by visual inspection to ensure the clot was still in place.

After treatment, the patella ligament, subcutaneous tissue and skin were sutured, and subcutaneous lidocaine was injected for pain management. The animals were treated postoperatively with Finadyne 5\% (Flunixin meglumin, $1.1 \mathrm{mg} / \mathrm{kg}$, oral paste, Intervet, Denmark) for 5 days and were allowed immediate weight-bearing and full-range of motion postoperatively. Trained animal keepers, supervised by a veterinarian, closely observed each animal thrice daily. After 6 months the animals were euthanized using Pentobarbital $(0.4 \mathrm{~mL} / \mathrm{kg})$ and osteochondral blocks of $1 \mathrm{~cm} \times 1 \mathrm{~cm} \times 1 \mathrm{~cm}$ around the defect were cut for further analyses.

\section{Preparation of specimens}

The samples were prepared as previously described in detail [22]. In brief, samples were dehydrated in ethanol of increasing concentration (70\%-96\%) and cleared in isopropanol and xylene. The samples were then embedded in methyl methacrylate (MMA).

\section{$\mu \mathrm{CT}$}

The MMA embedded osteochondral blocks were scanned in a desktop $\mu \mathrm{CT}$ scanner (Scanco $\mu \mathrm{CT}$ 35; Scanco Medical, Brüttiselen, Switzerland) with an isotropic voxel size of $10 \mu \mathrm{m}, \mathrm{X}$-ray voltage of $55 \mathrm{kV}$, current of $145 \mu \mathrm{A}$, and an integration time of $800 \mathrm{~ms}$ in high resolution mode $\left(1000\right.$ projections $\left./ 180^{\circ}\right)$. The trabecular bone was analyzed by drawing a $2-\mathrm{mm}$-high cylindrical VOI (volume of interest) with a diameter of 6 $\mathrm{mm}$ in the trabecular bone beneath the defect using a custom-made computer program running under Linux [23]. The VOI was imported into the software provided with the scanner (IPL version 6.5). The 3D data sets were low-pass filtered using a Gaussian filter $(\sigma=1.3$, support $=2$ ) in order to remove noise before segmentation with a fixed threshold filter (threshold $=510.3 \mathrm{mg}$ $\mathrm{HA} / \mathrm{cm}^{3}$ ).

Analyses included bone volume fraction (BV/TV), trabecular thickness (Tb.Th), trabecular number (Tb.N), trabecular separation (Tb.Sp), connectivity density (CD), structure model index (SMI), and bone material density ( $)$.

\section{Histologic evaluation}

The MMA embedded osteochondral blocks were cut into $7-\mu \mathrm{m}$-thick sections by use of a hard tissue microtome (Reichert Jung Polycot). All samples were stained with hematoxylin and eosin, safranin $\mathrm{O}$, toluidine blue and immunohistochemically stained for collagen type I or II. All evaluations were done by a single, blinded assessor with experience in experimental cartilage repair.

\section{Histomorphometry}

The morphological characteristics of the repair tissue were quantitatively evaluated by means of histomorphometry as described by Foldager et al. [24]. Each defect was halved, and sections were cut for every $350 \mu \mathrm{m}$, yielding 7 sections per defect. A $5 \times 5$ point counting grid was superimposed onto each section at $\times 10$ magnification (newCAST software; Visiopharm), and 50\% of the defect was counted according to tissue type (hyaline cartilage, fibrocartilage, fibrous tissue, bone, or vascular tissue) as previously described in detail using hematoxylin and eosin staining with polarized light to accentuate collagen fibers [22]. Hyaline cartilage was defined as rounded cells in lacunae within a hyaline matrix, fibrocartilage as rounded cells in lacunae within a fibrous matrix and fibrous tissue as elongated cells in a fibrous matrix.

Metachromasia on safranin-O staining was furthermore analyzed on a single, central section per defect and the percentage of repair tissue with metachromasia was determined $[8,17]$.

\section{Semiquantitative scoring}

Blinded evaluation of a central section of each defect by use of the ICRS II histological score was performed. In the ICRS II score, the sections are evaluated with a visual analog scale from 0 (severely abnormal) to 100 (normal) compared to normal hyaline cartilage. There are 14 categories: tissue morphological characteristics, matrix staining, cell morphological characteristics, chondrocyte clustering, surface architecture, basal integration, formation of a tidemark, subchondral bone abnormalities, inflammation, abnormal calcification, vascularization, surface assessment, deep zone assessment, and overall assessment [20]. Safranin $O$ and toluidine blue staining was used for the ICRS II evaluation.

\section{Immunohistochemistry}

Immunohistochemical staining was performed on central sections with polyclonal rabbit antibodies for collagen type I (Abcam, Ab 34,710, Cambridge, UK) and collagen type II (Neomarkers, MS 306-P0, Fremont, CA) was performed as previously described using a Dako Autosatiner (Dako Universal Staining System, Carpinteria, CA) [25]. Negative staining controls were labeled with rabbit serum (Dako, X0902) or mouse IgG isotype control (Thermo Fisher Scientific, Camarillo, CA), respectively. For labeling streptavidin-horse radish peroxidase and aminoethyl carbazole was used according to the manufacturer's instructions (Dako). The sections were counterstained with Mayer's hematoxylin. A visual analog scale (0-100) was used to evaluate the percentage of positively stained repair tissue for collagen type I and II for each sample [20]. The amount of positively stained 
tissue was ranged in quartiles from 0 to $25 \%, 25-50 \%$, $50-75 \%$ or $75-100 \%$.

\section{Statistical analysis}

Sample size was determined by power analysis based on overall ICRS II score as primary endpoint. Based on recent studies we expected that BMS without enhancement would score 10 points and enhanced BMS would score 30 points. SD for the ICRS II score was expected to be 15 points. Power was set to $80 \%, \alpha=0.05$ and $\beta=$ 0.2 . With these assumption nine treatment units per study group was needed. We decided to include 12 units per group to account for possible animal dropout.

For measures of cartilage repair (histomorphometry and histology (ICRS score)), a mixed-effect model was fitted to the data, with pig and knee (left or right) treated as random effects, and treatment (BMS or $\mathrm{CB}$ ) and defect site (proximal/lateral or distal/medial) as fixed effects. A $p$-value of less than 0.05 was considered significant. Each category from the ICRS II score was analyzed separately. $\mu \mathrm{CT}$ data was compared using unpaired t-tests. The number of samples in each quartile of positive collagen staining was analyzed using Fisher's exact test. Two-tailed $p$-values less than 0.05 were considered significant. Statistical analysis was performed using STATA version 15.0 (StataCorp, College Station, TX, USA) and Prism 7 (GraphPad Software, Inc.).

\section{Results}

All animals went through 6 months follow-up and there were no per- or postoperative complications.

Repair tissue was irregular and opaque and was easily distinguishable from the native cartilage in both treatment groups (supplementary Fig. 1+2). One defect/specimen from each group was lost due to theft while being transported for $\mu \mathrm{CT}$.

\section{$\mu \mathrm{CT}$}

Defects treated with $\mathrm{CB}$ had significantly thicker trabeculae $(170 \mu \mathrm{m}$ vs. $150 \mu \mathrm{m}, p=0.029)$ and the bone had significantly higher bone material density $(861 \mathrm{mg} \mathrm{HA} /$ $\mathrm{cm}^{3}$ vs. $845 \mathrm{mg} \mathrm{HA} / \mathrm{cm}^{3}, p=0.028$ ) indicating that the bone was more mineralized (Table 1 and Fig. 2).

There were no statistically significant differences in the other measured parameters (bone volume fraction (BV/TV), trabecular number (Tb.N), trabecular separation (Tb.Sp), connectivity density (CD), and structure model index (SMI)).

\section{Histomorphometry}

Histomorphometric analysis revealed significantly more fibrocartilage $(80 \%$ vs $64 \%, p=0.039)$ and a trend towards less fibrous tissue in the defects treated with $\mathrm{CB}$ $(15 \%$ vs $30 \%, p=0.052)$ (Fig. 3). Hyaline cartilage was
Table $1 \mu C T$ data \pm standard deviations. ${ }^{*}$ and bold $=$ parameters with significant differences. BMS = bone marrow stimulation

\begin{tabular}{|c|c|c|}
\hline Parameter & BMS & BMS + CARGEL \\
\hline Bone volume fraction (BV/TV) & $0.471 \pm 0.01$ & $0.499 \pm 0.07$ \\
\hline Connectivity density (CD) $\left(1 / \mathrm{mm}^{3}\right)$ & $29.67 \pm 6.87$ & $26.17 \pm 3.78$ \\
\hline Trabecular number (Tb N) (1/mm) & $3.198 \pm 0.17$ & $3.101 \pm 0.40$ \\
\hline Trabecular thickness (Tb Th) $(\mathrm{mm})^{*}$ & $0.148 \pm 0.01$ & $0.168 \pm 0.01$ \\
\hline Trabecular spacing (Tb Sp) (mm) & $0.272 \pm 0.03$ & $0.285 \pm 0.04$ \\
\hline Bone material density $\left(\mathrm{mg} \mathrm{HA} / \mathrm{cm}^{3}\right)^{*}$ & $845.4 \pm 5.61$ & $861.4 \pm 9.59$ \\
\hline Structure model index (SMI) & $-1.710 \pm 0.13$ & $-2.155 \pm 1.02$ \\
\hline
\end{tabular}

only seen in one defect treated with $\mathrm{CB}$ and none treated with BMS alone. No significant differences were seen for bone ( $2 \%$ vs $5 \%, p=$ n.s. (not significant)), or marrow ( $3 \%$ vs $1 \%, p=$ n.s.). No significant differences were seen between proximal, lateral and distal, medial defects. On single slides centrally in the defects there were no significant differences in metachromasia on safranin-O staining between the two treatment groups ( $47 \%$ vs $37 \%, p=$ n.s.).

\section{Semiquantitative scoring}

Complete or almost complete filling was found histologically in all defects. Best, average and worst examples of both treatments are shown in Fig. 4. In general, ICRS II scores were good for chondrocyte clustering and abnormal calcification/ossification even though two defects in the BMS group had small osteophytes in the repair tissue area (Fig. 5). No significant differences were seen between proximal, lateral and distal, medial defects for any categories. Cartilage and subchondral bone histology were altered for both groups as observed on tissue morphology, matrix staining, cell morphology, surface architecture and tidemark formation. There were no differences between the overall assessments. "Subchondral bone abnormalities/marrow fibrosis" (44 vs. 69, $p=$ 0.043) scored significantly lower in defects treated with $\mathrm{CB}$. All defects had altered subchondral bone seen as small osteophytes or an irregular subchondral bone plate. Alterations in the subchondral bone plate ranged from almost complete restoration to intense remodeling with fibrovascular infiltration in the marrow space. Six of 11 defects treated with $\mathrm{CB}$ had pronounced changes in the subchondral bone, while this was only seen in one defect treated with BMS alone. Three defects in the $\mathrm{CB}$ group, in three different minipigs, had infiltration of fat into the defect area (Fig. 6). There was a trend towards a lower score on "Basal integration" in defects treated with $\mathrm{CB}$, however, the difference was not statistically significant (53 vs 71, $p=0.069$ ). Basal integration ranged from almost full basal integration to very little basal integration. There were no significant differences in any other 


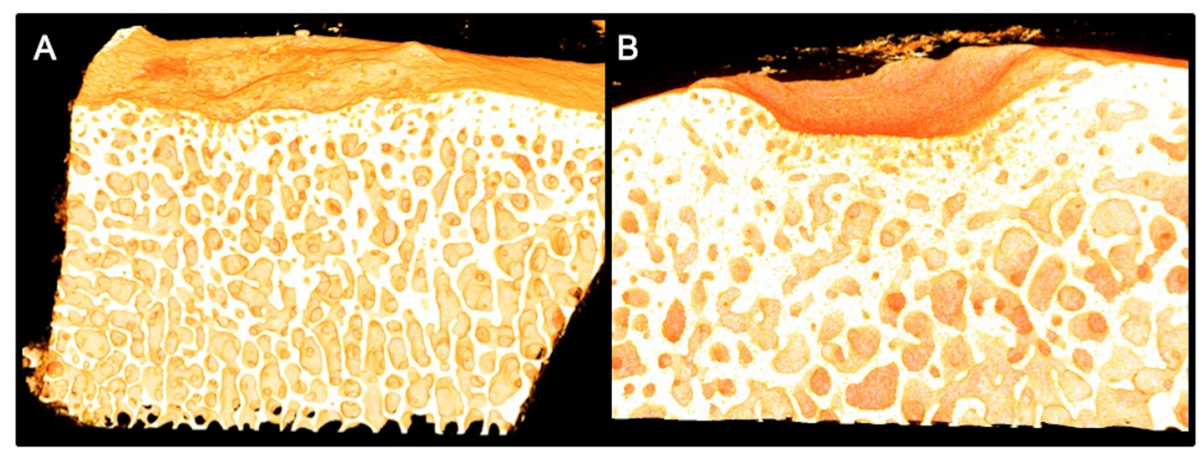

Fig. 2 a shows a $\mu C T$ image of a defect treated with BMS alone showing almost completely restored subchondral bone plate. $\mathbf{b}$ shows a defect treated with CB with pronounced subchondral remodeling

subscales of the ICRS II score (Fig. 5). Inflammation and vascularization were not seen in any defect. There was a slight trend towards more matrix staining (56 vs $36, p=$ 0.184 ) and better tissue morphology (36 vs $27, p=0.151$ ) in the $\mathrm{CB}$ group.

\section{Immunohistochemistry}

Most defects in both groups had $<50 \%$ positive staining for collagen type I or II (Fig. 7, 8, and 9). There was a trend towards less staining for collagen type I and more staining for collagen type II in defects treated with $\mathrm{CB}$, however this was not statistically significant $(p=0.11$ and $p=0.08$, respectively).

\section{Discussion}

The main findings of this study are that addition of CARGEL Bioscaffold to bone marrow stimulation led to a significant increase in fibrocartilage and a trend towards reduced fibrous tissue in the cartilage repair tissue. In addition, the subchondral bone had thicker trabeculae and higher mineralized bone tissue in defects treated with $\mathrm{CB}$ and BMS. CB seemed to improve repair tissue and induce a more pronounced subchondral

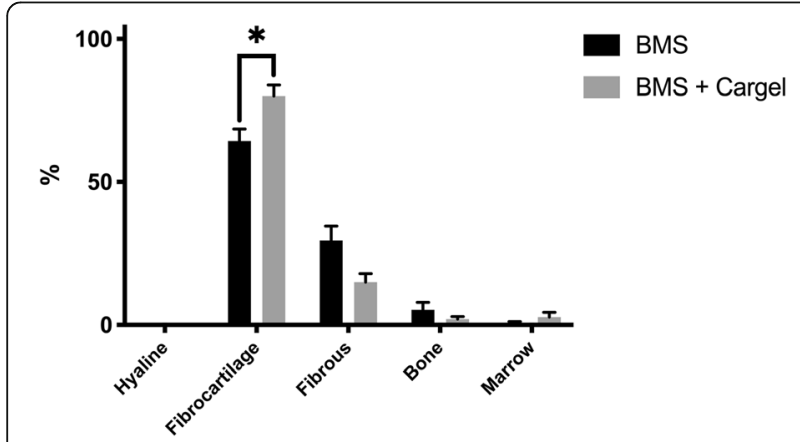

Fig. 3 Mean fraction of hyaline tissue, fibrocartilage, and fibrous tissue (+ standard error of mean (SEM)) in the cartilage repair tissue. $n=11$ for each group. BMS = bone marrow stimulation. Grey bar $=$ CARGEL Bioscaffold + BMS, black bar $=$ BMS only. ${ }^{*}=p<0.05$ remodeling. However, hyaline cartilage was not produced. Most ICRS II parameters and immunohistochemical stainings did not differ between the two treatment groups.

Only one other large animal study has been conducted with this chitosan hydrogel [8]. In that study a higher defect filling and a higher percentage of hyaline repair tissue in the $\mathrm{CB}$ group compared with a microfracture only group was found using an ovine model. In that study, however, it was assumed that tissue staining pink or red with safranin $\mathrm{O}$ was hyaline cartilage. Hoemann et al. reported $86 \%$ hyaline cartilage in the $\mathrm{CB}$ group and $71 \%$ in the microfracture group, which is in stark contrast to $<1 \%$ hyaline cartilage found in the repair tissue of both groups in the present study. We included single section histologic analysis using safranin-O to allow for comparison with the study by Hoemann et al. and found proportions of hyaline cartilage closer to what was reported in that study (47\% and 37\%) [8]. In the present study, however, we found no statistically significant differences between the groups. The limited fraction of hyaline cartilage in the present study is in line with other animal studies on cartilage repair [26-28]. In the present study we used polarized light and H\&E staining to quantitatively determine whether the repair tissue was hyaline cartilage, fibrocartilage or fibrous tissue. Use of polarized light was not described by Hoemann et al. and this may have led to an insufficient distinction between fibrocartilage and hyaline cartilage $[8,24]$.

It is also noteworthy that Hoemann et al. observed the best repair on the femoral condyles, whereas the trochlear defects, as used in our study, had significantly less hyaline repair tissue [8]. Another study conducted on New Zealand White Rabbits also reported more hyaline tissue after 6.5 months in defects filled with $\mathrm{CB}$ compared to BMS and thrombin. Here tissue staining red or pink was also assumed to be hyaline cartilage. Defects treated with $\mathrm{CB}$ also scored higher on the O'Driscoll score than the control group [17]. No differences were seen between proximal/ 


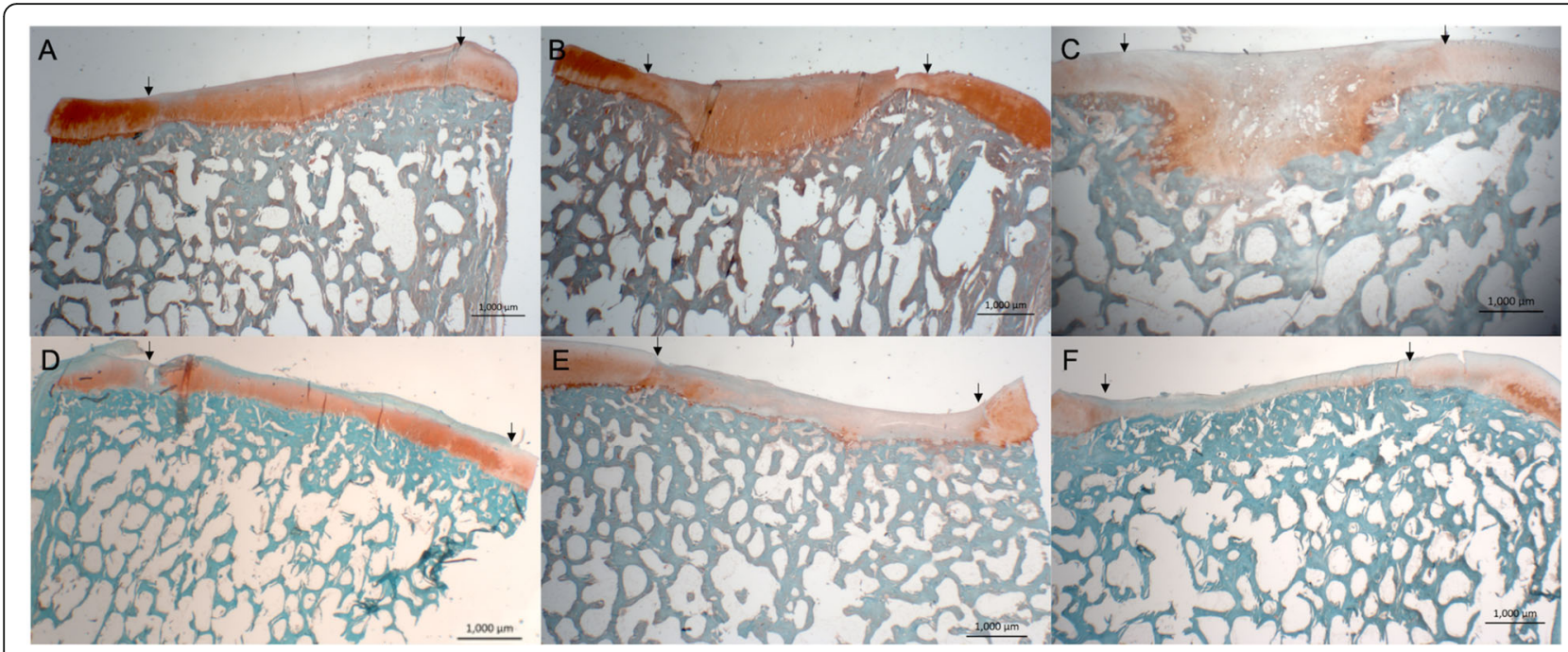

Fig. 4 Safranin O staining; scale bars: $1000 \mu \mathrm{m}$. Magnification 12.5-fold. Defects treated with CB (A-C) and BMS (D-F). Images represent best (left), average (middle) and worst (right) repair. A larger extent of subchondral remodeling is seen in the CB treated defects, whereas there also seems to be a higher degree of metachromasia in CB treated defects

lateral and distal/medial defects. Shear forces on the repair tissue may theoretically differ at these sites and a study on BioCartilage showed differing outcome on distal and proximal defects on the lateral trochlear ridge in an equine model [29]. Therefore, site (medial or lateral) was accounted as a fixed effect in the mixed model analysis. However, because we found no differences between prox$\mathrm{imal} /$ lateral and distal/medial defects, the results from all defects were counted together.

Clinical studies on CB have also showed an improvement in repair tissue quantity and quality on MRI and histological evaluation of biopsies of repair tissue, although a significant improvement in patient outcome after 5 years has not been seen $[9,10,30]$.

A varying degree of remodeling was seen in subchondral bone beneath the defects. Subchondral remodeling

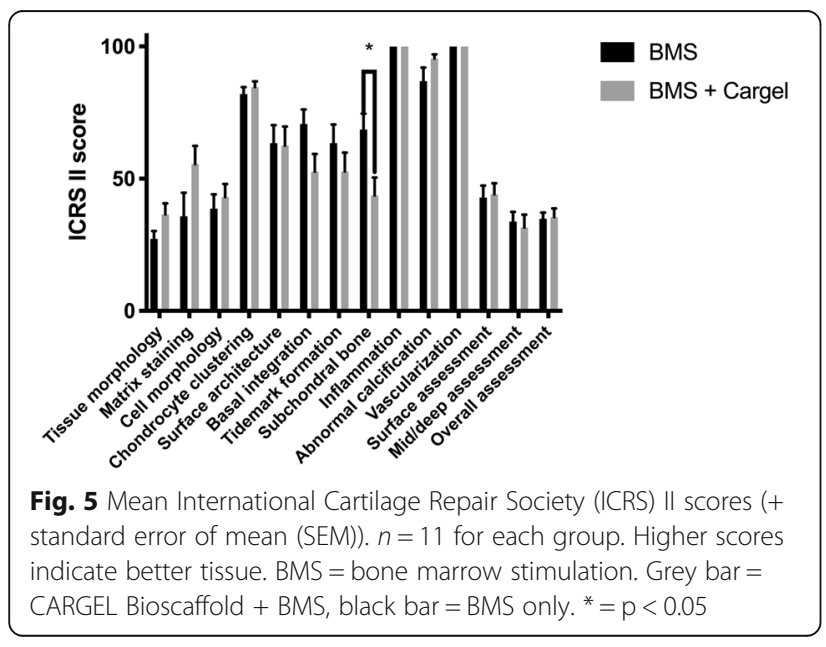

was pronounced in 6 of 11 defects treated with $C B$, whereas it was mild in all other defects, except for one, treated with BMS. Remodeling of the subchondral bone is a known possible "side effect" to cartilage repair techniques such as BMS as well as autologous chondrocyte implantation (ACI) and involves both bone overgrowth and development of intralesional cysts [31, 32]. This can lead to subchondral edema, lack of graft integration and treatment failure. Remodeling of the subchondral bone is often seen in animal models of cartilage repair and is most likely due to a combination of osteoclast activation, altered mechanical loading and access of the synovial fluid to the subchondral bone [33-36]. A larger degree of subchondral remodeling in the $\mathrm{CB}$ treated defects may be due to a larger bioactive response of the subchondral bone due to the chitosan in the CB scaffold. A study on $\mathrm{CB}$ reported that the addition of $\mathrm{CB}$ to $\mathrm{BMS}$ delayed maturation and ossification of chondrogenic foci in drill holes [7]. The authors argued that this may be due to the increased recruitment of neutrophils and altered macrophage activation in drill holes beneath chitosan implants [6,37]. Inflammation has been reported to delay callus formation in fracture repair models [38]' but delayed healing may promote regeneration by progenitor cells and thereby hinder development of fibrous scar tissue, thus leading to a better and more mature repair tissue [39]. Similarly, a study by Chen et al. compared different types of BMS in a rabbit model and found that increased subchondral bone activation and remodeling improved cartilage repair [33]. This is also in line with the findings in the present study where we found an increased subchondral bone activity and a better repair tissue with $\mathrm{CB}$ treatment compared with BMS alone. It is 


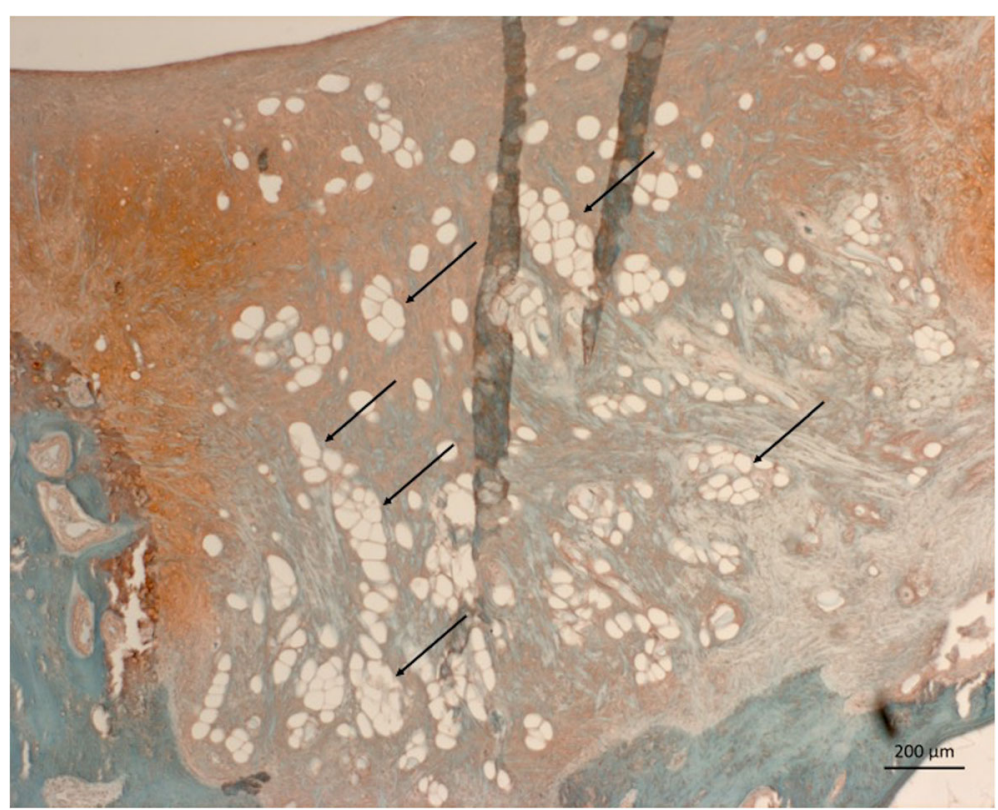

Fig. 6 Safranin O staining; scale bar $200 \mu \mathrm{m}$. Magnification 50-fold. Infiltration of marrow (arrows), seen as fat, into a CB treated defect

possible that with longer follow-up the subchondral bone and cartilage repair tissue would have improved further.

The $\mu \mathrm{CT}$ analysis revealed thicker trabeculae in the CB group. The above-mentioned study by Marchand et al. of $\mathrm{CB}$ in New Zealand White Rabbits reported thicker trabeculae in defects with more residual holes after BMS [17]. Contrary to the findings in the present study, trabecular thickness was higher in the control group compared with $\mathrm{CB}$, but the control group also had more residual drill holes after drilling. It can be speculated whether the thicker trabeculae is caused by a direct response elicited by the $\mathrm{CB}$ or whether it is an indirect response to the altered mechanical loading due to the pronounced alteration of the subchondral bone seen in more than half of the CB treated defects in our study [40]. The differences in the subchondral bone and subsequently the thicker trabeculae found in our study may be a result of faster bone turnover rates in New Zealand White Rabbits compared with Göttingen Minipigs [41].

The higher bone material density, however, points towards more mature bone in the spongiosa beneath the subchondral bone plate in the defects treated with $\mathrm{CB}$. $\mathrm{CB}$ is a liquid before stabilization of the clot and has access to the bone and bone marrow through the drill holes. Residual chitosan may adhere to the calcified cartilage and bone and influence bone repair through increased cell recruitment $[6,8,16]$.
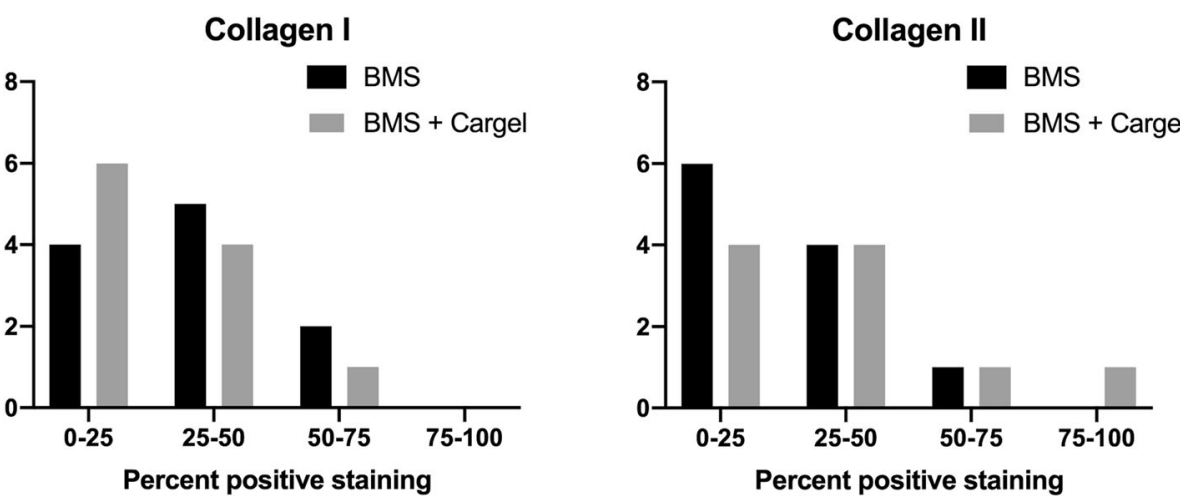

Fig. 7 Graph showing quartiles of positive collagen I (left) and collagen II (right) staining. Grey bar = CARGEL Bioscaffold + BMS, black bar = BMS only. The $y$-axis represents the number of samples with the quartile of positive staining. In normal hyaline cartilage low amounts of collagen type I and high amounts of collagen type I| is seen. BMS = bone marrow stimulation 


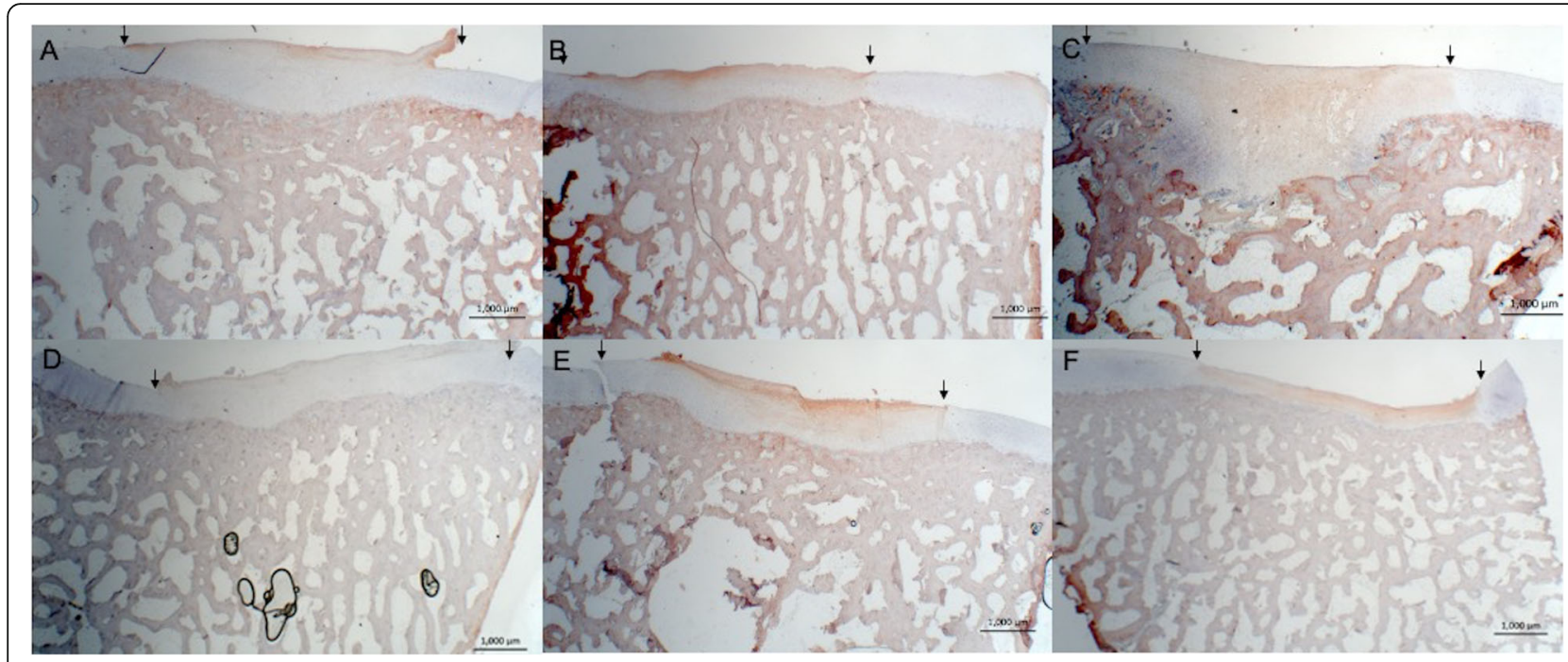

Fig. 8 Collagen I staining; scale bar $1000 \mu \mathrm{m}$. Magnification 12.5-fold. Defects treated with CB (a-c) and BMS (d-f). Images represent 0-25\% (left), 25-50\% (middle) and 50-75\% (right) positive collagen I staining

Adipose tissue was present in three defects treated with CB. Adipose tissue has not been mentioned in any of the previous literature on $\mathrm{CB}[7,8,14,15,17,30,33$, $34,37,42-45]$. The presence of adipose tissue in the repair tissue area is of course an unwanted response to BMS. It has occasionally been seen in animal models of BMS $[15,37]$. So, whether the presence of adipose tissue was related to $\mathrm{CB}$ is impossible to conclude. MSCs from the bone marrow are defined by their ability to undergo differentiation into different cell types such as chondrocytes, adipocytes, or osteocytes depending on humeral environment and this may explain the fat infiltration [46]. Chitosan has been shown to influence fat metabolism when used as dietary supplement and this effect could perhaps also be exerted by local application as in the present study [47].

A trend towards more collagen type II (indicative of hyaline cartilage) and less collagen type I (indicative of fibrous tissue/bone) was seen in $\mathrm{CB}$ treated defects. However, no significant differences were seen in the immunohistochemical stainings for collagen type I and II. The trend was, however, in line with the histomorphometric results showing more fibrocartilage in the $\mathrm{CB}$ treated defects. Staining for collagen type II generally correlated well with the metachromasia seen on Safranin $\mathrm{O}$ stained sections. While immunohistochemical staining for collagen type I and II can be an important tool in the analysis of cartilage repair tissue, limitations exist with

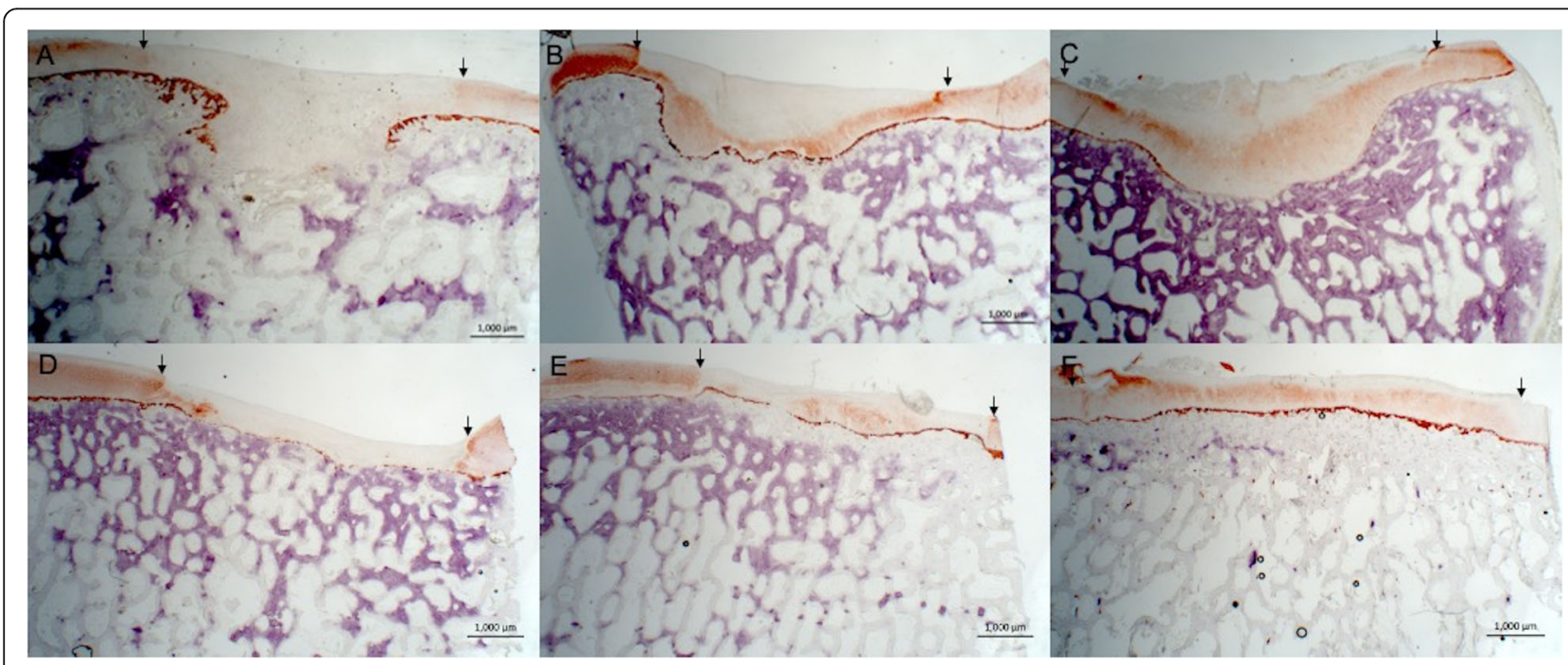

Fig. 9 Collagen II staining; scale bar $1000 \mu \mathrm{m}$. Magnification 12.5-fold. Defects treated with CB (a-c) and BMS (d-f). Images represent 0-25\% (left), 25-50\% (middle) and 50-75\% (right) positive collagen II staining 
regards to immunohistochemistry as a loss of antigenicity may occur and weak staining may be seen $[48,49]$. This limited our ability to quantify the amount of positive staining accurately and was the reason for using quartiles. This, naturally, reduced the chances of finding significant differences. That most defects stained $<50 \%$ positive for collagen type II was in line with other studies with BMS in minipigs $[20,36,50]$. Some of the repair tissue did not stain positively for either collagen type I or type II and this may indicate the presence of an immature repair tissue containing other combinations of collagens [51, 52].

A strength of the study was that it was performed in a validated large animal model with comprehensive investigation of repair tissue quality and subchondral bone response including $\mu \mathrm{CT}$, histomorphometry, histology, and immunohistochemistry. The existing literature on $\mathrm{CB}$ is primarily based on rabbit models, whereas literature on large animal models is sparse. With larger animal models, as the porcine, joint size and gait characteristics more closely resembles the human, but costs are significantly increased $[18,53,54]$.. This offers great translational value, but also adds limitations due to the costs. Nevertheless, using a validated, large animal model these comprehensive repair tissue analyses can deliver data that are not possible to obtain in clinical studies. The treatment tested has already been used in the clinic for a few years and has proven safe and shown promising results with regards to patient outcome, repair tissue quality, and quantity $[9,12,30]$. The present study therefore adds to the understanding of the promising clinical outcomes with findings of increased fibrocartilage tissue formation and more repair tissue-supportive subchondral bone remodeling. It must though again be emphasized that no true hyaline cartilage was observed in repair tissues. Furthermore, large variations were seen in outcome on several parameters. This is often seen in large animal studies and may be an inherent limitation of large animal studies and is important to take into account when determining the number of animals/defects pr. treatment group in in vivo studies $[21,22,28,35,50$, 53]. Great variations in outcome with cartilage repair treatments is also seen in the clinical setting, but here it can, to some degree, be explained by patient (age, sex, $\mathrm{BMI}$ ) and lesions (site, size) demographics.

Limitations to our study are that we only had one time point of evaluation making us unable to observe the temporal changes and degradation of the scaffold. The repair tissue may furthermore require more than 6 months for maturation [18]. The choice of only a single time point was mainly cost related. The follow-up period of 6 months is naturally significantly shorter than that used in clinical studies, but is considered sufficient for organized cartilage repair in minipigs $[55,56]$. Other studies have, however, pointed towards changes in the biological repair between 6 and 12 months [18, 57]. Other limitations of the study include a lack of mechanical testing, which could have provided insight into the biomechanical properties of the repair tissue and the lack of immobilization after surgery as recommended in the clinic. Rehabilitation is highly important clinically with reduced loading of areas of repair recommended. However, immobilization is not possible in Göttingen minipigs $[20,58]$. This may lead to an overload of repair tissue and a reduced healing response. An untreated control group was not included as the defects were of critical size, which are well-documented to fill with mainly fibrous tissue in Göttingen minipigs $[18,19,56]$.

In conclusion, use of CARGEL Bioscaffold in combination with bone marrow stimulation did not lead to formation of hyaline cartilage but does seem to induce an improved repair tissue and a more pronounced subchondral bone remodeling compared with bone marrow stimulation alone, which may be a predictor for improved repair tissue.

\section{Supplementary information}

Supplementary information accompanies this paper at https://doi.org/10. 1186/s40634-020-00245-7.

Additional file 1 Supplementary figure 1. Macroscopic images of the 6 knees treated with bone marrow stimulation alone.

Additional file $\mathbf{2}$ Supplementary figure 2. Macroscopic images of the 6 knees treated with bone marrow stimulation in combination with CARGEL Bioscaffold.

\section{Abbreviations}

BMS: Bone marrow stimulation; Mfx: Microfracture; CB: CARGEL Bioscaffold; ICRS: International Cartilage Repair Society; ACl: Autologous chondrocyte implantation

\section{Acknowledgements}

The authors would like to thank Niels Trolle from Department of Public Health, Aarhus University, for assistance with the statistical analyses and laboratory technician Anette Baatrup at the Orthopaedic Research Laboratory, Aarhus University Hospital, for her help and cooperation.

\section{Animal welfare}

The study was approved by the Danish Law on Animal Experimentation.

\section{Authors' contributions}

$\mathrm{KH}$ : contributed to formulation of the scientific problem, planning and performing the animal surgeries, analyses and interpretation of results and manuscript preparation and finalization. BBC: contributed to formulation of the scientific problem, planning and performing the animal surgeries and interpretation of results. MLO: contributed to planning and performing the animal surgeries and interpretation of results. JST: performed $\mu C T$ scanning and contributed to analyses and interpretation of $\mu \mathrm{CT}$ data. CBF: contributed to formulation of the scientific problem, performing the animal surgeries and interpretation of results. MCL: contributed to formulation of the scientific problem and interpretation of results. All authors read and approved the final manuscript.

\section{Funding}

This study was financially supported by the Danish Rheumatism Association, and "Direktør Emil C. Hertz og Hustru Inger Hertz' Fond". The $\mu C T$ scanner 
was donated by the VELUX Foundation. The funding bodies were not involved in the study in any way.

\section{Availability of data and materials}

The datasets used and/or analysed during the current study are available from the corresponding author on reasonable request.

\section{Ethics approval and consent to participate}

The study was approved by the Danish Ministry of Justice Ethical Committee (J.nr. 2017-15-0201-01343).

\section{Consent for publication}

Not applicable.

\section{Competing interests}

The authors declare that there are no conflicts of interest.

\section{Author details}

'Orthopedic Research Laboratory, Aarhus University Hospital, Palle Juul-Jensens Boulevard 99, Section J, Level 1, 8200 Aarhus N, Denmark. ${ }^{2}$ Department of Biomedicine, Aarhus University, Wilhelm Meyers Allé 3, 8000 Aarhus C, Denmark. ${ }^{3}$ Sports Trauma Clinic, Aarhus University Hospital, Palle Juul-Jensens Boulevard 99, Section J, Level 1, 8200 Aarhus N, Denmark.

Received: 23 January 2020 Accepted: 28 April 2020

Published online: 08 May 2020

\section{References}

1. Buckwalter JA, Mankin HJ (1998) Articular cartilage: degeneration and osteoarthritis, repair, regeneration, and transplantation. Instr Course Lect 47:487-504

2. Farr J, Cole B, Dhawan A, Kercher J, Sherman S (2011) Clinical cartilage restoration: evolution and overview. Clin Orthop Relat Res 469:2696-2705. https://doi.org/10.1007/s11999-010-1764-z

3. Mithoefer K, McAdams T, Williams RJ, Kreuz PC, Mandelbaum BR (2009) Clinical Efficacy of the Microfracture Technique for Articular Cartilage Repair in the Knee. Am J Sports Med 37:2053-2063. https://doi.org/10.1177/ 0363546508328414

4. Arshi A, Fabricant PD, Go DE, Williams RJ, McAllister DR, Jones KJ (2017) Can Biologic Augmentation Improve Clinical Outcomes Following Microfracture for Symptomatic Cartilage Defects of the Knee? A Systematic Review. Cartilage 194760351774672. https://doi.org/10.1177/1947603517746722

5. Steinwachs MR, Waibl B, Mumme M (2014) Arthroscopic Treatment of Cartilage Lesions With Microfracture and BST-CarGel. Arthrosc Tech 3:e399e402. https://doi.org/10.1016/j.eats.2014.02.011

6. Chevrier A, Hoemann CD, Sun J, Buschmann M Chitosaneglycerol phosphate/blood implants increase cell recruitment, transient vascularization and subchondral bone remodeling in drilled cartilage defects. https://doi.org/10.1016/j.joca.2006.08.007

7. Chevrier A, Hoemann CD, Sun J, Buschmann MD, Bryant T, Awad H, al. et (2011) Temporal and spatial modulation of chondrogenic foci in subchondral microdrill holes by chitosan-glycerol phosphate/blood implants. Osteoarthr Cartil 19:136-144. doi: https://doi.org/10.1016/j.joca. 2010.10 .026

8. Hoemann CD, Hurtig M, Rossomacha E, Sun J, Chevrier A, Shive MS, Buschmann MD (2005) Chitosan-Glycerol Phosphate/Blood Implants Improve Hyaline Cartilage Repair in Ovine Microfracture Defects:87. https:// doi.org/10.2106/JBJS.D.02536

9. Shive MS, Stanish WD, McCormack R, Forriol F, Mohtadi N, Pelet S, Desnoyers J, Méthot S, Vehik K, Restrepo A (2015) BST-CarGel ${ }^{\oplus}$ Treatment Maintains Cartilage Repair Superiority over Microfracture at 5 Years in a Multicenter Randomized Controlled Trial. Cartilage 6:62-72. https://doi.org/ $10.1177 / 1947603514562064$

10. Stanish WD, Mccormack R, Forriol F, Mohtadi N, Pelet S, Desnoyers J, Restrepo A, Shive MS, Desnoyers J, Restrepo A, Shive MS (2013) Novel Scaffold-Based BST-CarGel Treatment Results in Superior Cartilage Repair Compared with Microfracture in a Randomized Controlled Trial. 95:16401650. https://doi.org/10.2106/JBJS.L.01345

11. Steinwachs M, Cavalcanti N, Mauuva S, Reddy V, Werner C, Tschopp D, Choudur HN (2018) Arthroscopic and open treatment of cartilage lesions with BST-CARGEL scaffold and microfracture: A cohort study of consecutive patients. https://doi.org/10.1016/j.knee.2018.11.015
12. Rhee C, Amar E, Glazebrook M, Coday C, Wong IH (2018) Safety Profile and Short-term Outcomes of BST-CarGel as an Adjunct to Microfracture for the Treatment of Chondral Lesions of the Hip. Orthop J Sport Med 6: 2325967118789871. https://doi.org/10.1177/2325967118789871

13. Frappier J, Stanish W, Brittberg M, Steinwachs M, Crowe L, Castelo D, Restrepo A (2014) Economic evaluation of BST-CarGel as an adjunct to microfracture vs microfracture alone in knee cartilage surgery. J Med Econ 17:266-278. https://doi.org/10.3111/13696998.2014.897626

14. Bell AD, Hurtig MB, Quenneville E, Rivard G-É, Hoemann CD (2017) Effect of a Rapidly Degrading Presolidified $10 \mathrm{kDa}$ Chitosan/Blood Implant and Subchondral Marrow Stimulation Surgical Approach on Cartilage Resurfacing in a Sheep Model. Cartilage 8:417-431. https://doi.org/10.1177/1947603516676872

15. Bell AD, Lascau-Coman V, Sun J, Chen G, Lowerison MW, Hurtig MB, Hoemann CD (2013) Bone-Induced Chondroinduction in Sheep Jamshidi Biopsy Defects with and without Treatment by Subchondral Chitosan-Blood Implant: 1-Day, 3-Week, and 3-Month Repair. Cartilage 4:131-143. https:// doi.org/10.1177/1947603512463227

16. Hoemann CD, Sun J, McKee MD, Chevrier A, Rossomacha E, Rivard G-e, Hurtig M, Buschmann M, Hoemann CD, Sun J, McKee MD, Chevrier A, Rossomacha E, Rivard G-E, Hurtig M, Buschmann MD (2007) Chitosanglycerol phosphate/blood implants elicit hyaline cartilage repair integrated with porous subchondral bone in microdrilled rabbit defects. Osteoarthr Cartil 15:78-89. https://doi.org/10.1016/j.joca.2006.06.015

17. Marchand C, Chen G, Tran-Khanh N, Sun J, Chen H, Buschmann MD, Hoemann CD (2012) Microdrilled Cartilage Defects Treated with ThrombinSolidified Chitosan/Blood Implant Regenerate a More Hyaline, Stable, and Structurally Integrated Osteochondral Unit Compared to Drilled Controls. Tissue Eng Part A 18:508-519. https://doi.org/10.1089/ten.tea.2011.0178

18. Gotterbarm T, Breusch SJ, Schneider U, Jung M (2008) The minipig model for experimental chondral and osteochondral defect repair in tissue engineering: Retrospective analysis of 180 defects. Lab Anim 42:71-82. https://doi.org/10.1258/la.2007.06029e

19. Christensen $B B$, Foldager CB, Olesen ML, Vingtoft L, Rölfing JHD, Ringgaard S, Lind M (2015) Experimental articular cartilage repair in the Göttingen minipig: the influence of multiple defects per knee. J Exp Orthop 2:13. https://doi.org/10.1186/s40634-015-0031-3

20. Christensen BB, Olesen ML, Lind M, Foldager CB (2017) Autologous Cartilage Chip Transplantation Improves Repair Tissue Composition Compared With Marrow Stimulation. Am J Sports Med 45:1490-1496. https://doi.org/10. $1177 / 0363546517694617$

21. Olesen ML, Christensen BB, Foldager CB, Hede KC, Jørgensen NL, Lind M (2019) No Effect of Platelet-Rich Plasma Injections as an Adjuvant to Autologous Cartilage Chips Implantation for the Treatment of Chondral Defects. Cartilage 194760351986531. https://doi.org/10.1177/ 1947603519865318

22. Christensen BB, Foldager CB, Olesen ML, Hede KC, Lind M (2016) Implantation of Autologous Cartilage Chips Improves Cartilage Repair Tissue Quality in Osteochondral Defects. Am J Sports Med 44:1597-1604. https:// doi.org/10.1177/0363546516630977

23. Sikjaer T, Rejnmark L, Thomsen JS, Tietze A, Brüel A, Andersen G, Mosekilde $L$ (2012) Changes in 3-dimensional bone structure indices in hypoparathyroid patients treated with PTH (1-84): A randomized controlled study. J Bone Miner Res 27:781-788. https://doi.org/10.1002/jbmr.1493

24. Foldager CB, Nyengaard JR, Lind M, Spector M (2015) A Stereological Method for the Quantitative Evaluation of Cartilage Repair Tissue. Cartilage 6:123-132. https://doi.org/10.1177/1947603514560655

25. Foldager CB, Toh WS, Gomoll AH, Olsen BR, Spector M (2014) Distribution of Basement Membrane Molecules, Laminin and Collagen Type IV, in Normal and Degenerated Cartilage Tissues. Cartilage 5:123-132. https://doi.org/10. 1177/1947603513518217

26. Breinan HA, Martin SD, Hsu HP, Spector M (2000) Healing of canine articular cartilage defects treated with microfracture, a type-II collagen matrix, or cultured autologous chondrocytes. J Orthop Res 18:781-789. https://doi. org/10.1002/jor.1100180516

27. Miller RE, Grodzinsky AJ, Barrett MF, Hung H-H, Frank EH, Werpy NM, Mcllwraith CW, Frisbie DD (2014) Effects of the combination of microfracture and self-assembling Peptide filling on the repair of a clinically relevant trochlear defect in an equine model. J Bone Joint Surg Am 96: 1601-1609. https://doi.org/10.2106/JBJS.M.01408

28. Olesen ML, Christensen BB, Foldager CB, Hede KC, Bergholt NL, Lind M (2020) No effect of platelet-rich plasma as adjuvant to bone marrow stimulation for 
the treatment of chondral defects in a large animal model. Arch Orthop Trauma Surg 140:77-84. https://doi.org/10.1007/s00402-019-03292-7

29. Fortier LA, Chapman HS, Pownder SL, Roller BL, Cross JA, Cook JL, Cole BJ (2016) BioCartilage Improves Cartilage Repair Compared With Microfracture Alone in an Equine Model of Full-Thickness Cartilage Loss. Am J Sports Med 44:2366-2374. https://doi.org/10.1177/0363546516648644

30. Méthot S, Changoor A, Tran-Khanh N, Hoemann CD, Stanish WD, Restrepo A, Shive MS, Buschmann MD (2016) Osteochondral Biopsy Analysis Demonstrates That BST-CarGel Treatment Improves Structural and Cellular Characteristics of Cartilage Repair Tissue Compared With Microfracture. Cartilage 7:16-28. https://doi.org/10.1177/1947603515595837

31. Cole BJ, Farr J, Winalski CS, Hosea T, Richmond J, Mandelbaum B, De Deyne PG (2011) Outcomes After a Single-Stage Procedure for Cell-Based Cartilage Repair. Am J Sports Med 39:1170-1179. https://doi.org/10.1177/ 0363546511399382

32. Minas T, Gomoll AH, Rosenberger R, Royce RO, Bryant T (2009) Increased Failure Rate of Autologous Chondrocyte Implantation After Previous Treatment With Marrow Stimulation Techniques. Am J Sports Med:37. https://doi.org/10.1177/0363546508330137

33. Chen G, Sun J, Lascau-Coman V, Chevrier A, Marchand C, Hoemann CD (2011) Acute Osteoclast Activity following Subchondral Drilling Is Promoted by Chitosan and Associated with Improved Cartilage Repair Tissue Integration. Cartilage 2:173-185. https://doi.org/10.1177/1947603510381096

34. Chen H, Chevrier A, Hoemann CD, Sun J, Ouyang W, Buschmann MD (2011) Characterization of Subchondral Bone Repair for Marrow-Stimulated Chondral Defects and Its Relationship to Articular Cartilage Resurfacing. Am J Sports Med 39:1731-1741. https://doi.org/10.1177/0363546511403282

35. Fisher MB, Belkin NS, Milby AH, Henning EA, Bostrom M, Kim M, Pfeifer C, Meloni G, Dodge GR, Burdick JA, Schaer TP, Steinberg DR, Mauck RL (2015) Cartilage repair and subchondral bone remodeling in response to focal lesions in a mini-pig model: implications for tissue engineering. Tissue Eng Part A 21:850-860 10.1089/ten. TEA.2014.0384

36. Pfeifer CG, Fisher MB, Saxena V, Kim M, Henning EA, Steinberg DA, Dodge GR, Mauck RL (2017) Age-Dependent Subchondral Bone Remodeling and Cartilage Repair in a Minipig Defect Model. Tissue Eng Part C Methods 23: 745-753. https://doi.org/10.1089/ten.tec.2017.0109

37. Hoemann CD, Chen G, Marchand C, Tran-Khanh N, Thibault M, Chevrier A, Sun J, Shive MS, Fernandes MJG, Poubelle PE, Centola M, El-Gabalawy H (2010) Scaffold-Guided Subchondral Bone Repair. Am J Sports Med 38: 1845-1856. https://doi.org/10.1177/0363546510369547

38. Kratzel C, Bergmann C, Duda G, Greiner S, Schmidmaier G, Wildemann B (2008) Characterization of a rat osteotomy model with impaired healing. BMC Musculoskelet Disord 9:135. https://doi.org/10.1186/1471-2474-9-135

39. Gurtner GC, Werner S, Barrandon Y, Longaker MT (2008) Wound repair and regeneration. Nature 453:314-321. https://doi.org/10.1038/nature07039

40. Rath B, Nam J, Knobloch TJ, Lannutti JJ, Agarwal S (2008) Compressive forces induce osteogenic gene expression in calvarial osteoblasts. J Biomech 41:1095-1103. https://doi.org/10.1016/j.jbiomech.2007.11.024

41. Pearce A, Richards R, Milz S, Schneider E, Pearce S (2007) Animal models for implant biomaterial research in bone: A review. Eur Cells Mater 13:1-10. https://doi.org/10.22203/eCM.v013a01

42. Chen H, Sun J, Hoemann CD, Lascau-Coman V, Ouyang W, McKee MD, Shive MS, Buschmann MD (2009) Drilling and microfracture lead to different bone structure and necrosis during bone-marrow stimulation for cartilage repair. J Orthop Res 27:1432-1438. https://doi.org/10.1002/jor.20905

43. Guzmán-Morales J, Lafantaisie-Favreau C-H, Chen G, Hoemann CDD (2014) Subchondral chitosan/blood implant-guided bone plate resorption and woven bone repair is coupled to hyaline cartilage regeneration from microdrill holes in aged rabbit knees. Osteoarthr Cartil 22:323-333. https:// doi.org/10.1016/J.JOCA.2013.12.011

44. Hoemann CD, Tran-Khanh N, Chevrier A, Chen G, Lascau-Coman V, Mathieu C, Changoor A, Yaroshinsky A, McCormack RG, Stanish WD, Buschmann MD (2015) Chondroinduction Is the Main Cartilage Repair Response to Microfracture and Microfracture With BST-CarGel. Am J Sports Med 43:24692480. https://doi.org/10.1177/0363546515593943

45. Mathieu C, Chevrier A, Lascau-Coman V, Rivard GE, Hoemann CD (2013) Stereological analysis of subchondral angiogenesis induced by chitosan and coagulation factors in microdrilled articular cartilage defects. Osteoarthr Cartil 21:849-859. https://doi.org/10.1016/j.joca.2013.03.012

46. Minguell JJ, Erices A, Conget P (2001) Mesenchymal stem cells. Exp Biol Med (Maywood) 226:507-520
47. Liu S-H, Chiu C-Y, Shi C-M, Chiang M-T (2018) Functional Comparison of High and Low Molecular Weight Chitosan on Lipid Metabolism and Signals in High-Fat Diet-Fed Rats. Mar Drugs 16:251. https://doi.org/10.3390/ md16080251

48. de Matos LL, Trufelli DC, de Matos MGL, da Silva Pinhal MA (2010) Immunohistochemistry as an important tool in biomarkers detection and clinical practice. Biomark Insights 5:9-20. https://doi.org/10.4137/bmi.s2185

49. Yaziji H, Barry T (2006) Diagnostic Immunohistochemistry: What can Go Wrong? Adv Anat Pathol 13:238-246. https://doi.org/10.1097/01.pap. 0000213041.39070.2f

50. Kim IL, Pfeifer CG, Fisher MB, Saxena V, Meloni GR, Kwon MY, Kim M, Steinberg DR, Mauck RL, Burdick JA (2015) Fibrous Scaffolds with Varied Fiber Chemistry and Growth Factor Delivery Promote Repair in a Porcine Cartilage Defect Model. Tissue Eng Part A 21:2680-2690. https://doi.org/10. 1089/ten.tea.2015.0150

51. Eyre D (2002) Collagen of articular cartilage. Arthritis Res 4:30-35. https:// doi.org/10.1186/ar380

52. Eyre DR (2004) Collagens and Cartilage Matrix Homeostasis. Clin Orthop Relat Res 427:S118-S122. https://doi.org/10.1097/01.blo.0000144855.48640.b9

53. Chu CR, Szczodry M, Bruno S (2010) Animal models for cartilage regeneration and repair. Tissue Eng Part B Rev 16:105-115 10.1089/ten. TEB. 2009.0452

54. Hurtig MB, Buschmann MD, Fortier LA, Hoemann CD, Hunziker EB, Jurvelin JS, Mainil-Varlet P, Mcllwraith CW, Sah RL, Whiteside RA (2011) Preclinical Studies for Cartilage Repair: Recommendations from the International Cartilage Repair Society. Cartilage 2:137-152. https://doi.org/10.1177/ 1947603511401905

55. Harman BD, Weeden SH, Lichota DK, Brindley GW (2006) Osteochondral autograft transplantation in the porcine knee. Am J Sports Med 34:913-918. https://doi.org/10.1177/0363546505283257

56. Mainil-Varlet P, Rieser F, Grogan S, Mueller W, Saager C, Jakob RP (2001) Articular cartilage repair using a tissue-engineered cartilage-like implant: an animal study. Osteoarthr Cartil 9:S6-S15. https://doi.org/10.1053/joca.2001. 0438

57. Petersen JP, Ueblacker P, Goepfert C, Adamietz P, Baumbach K, Stork A, Rueger JM, Poertner R, Amling M, Meenen NM (2008) Long term results after implantation of tissue engineered cartilage for the treatment of osteochondral lesions in a minipig model. J Mater Sci Mater Med 19:20292038. https://doi.org/10.1007/s10856-007-3291-3

58. Hurst JM, Steadman JR, O'brien L, Rodkey WG, Acvs D, Briggs KK (2010) Rehabilitation Following Microfracture for Chondral Injury in the Knee. Clin Sports Med 29:257-265. https://doi.org/10.1016/j.csm.2009.12.009

\section{Publisher's Note}

Springer Nature remains neutral with regard to jurisdictional claims in published maps and institutional affiliations.

\section{Submit your manuscript to a SpringerOpen ${ }^{\circ}$ journal and benefit from:}

- Convenient online submission

- Rigorous peer review

- Open access: articles freely available online

- High visibility within the field

- Retaining the copyright to your article

Submit your next manuscript at $>$ springeropen.com 